Disponível em

http://www.anpad.org.br/rac

RAC, Curitiba, v. 15 , n. 2, art. 1, pp. 179-197, Mar./Abr. 2011

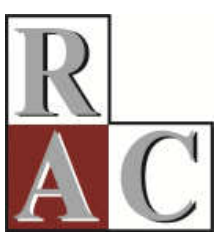

\title{
A Dimensão Histórica dos Discursos acerca do Empreendedor e do Empreendedorismo
}

\author{
The Historical Dimension of the Discourses Concerning the Entrepreneur and \\ Entrepreneurship
}

Alessandra Mello da Costa *

E-mail: amello9@terra.com.br IAG - PUC Rio Rio de Janeiro, RJ, Brasil.

Denise Franca Barros E-mail: denise.barros@fgv.br Fundação Getúlio Vargas - EBAPE/FGV Rio de Janeiro, RJ, Brasil.

José Luis Felicio Carvalho E-mail: zkcarvalho@hotmail.com Universidade Federal Rural do Rio de Janeiro - FACC/UFRJ Rio de Janeiro, RJ, Brasil.

* Endereço: Alessandra Mello da Costa

Rua Sambaíba, 350/103, Leblon, Rio de Janeiro/RJ, 22450-140.

Copyright (C) 2011 RAC. Todos os direitos, até mesmo de tradução, são reservados. É permitido citar parte de artigos sem autorização prévia, desde que seja identificada a fonte. 


\title{
Resumo
}

Este ensaio teórico busca identificar e discutir diferentes apropriações da ideia de empreendedorismo ao longo da história por meio dos discursos acerca do empreendedor e de seu papel na sociedade capitalista ocidental. Os contextos selecionados para reflexão são: (a) o período clássico de formação do capitalismo; (b) o advento do capitalismo monopolista; e (c) o capitalismo em sua atual configuração. Como os discursos não são neutros, a identificação de tais descontinuidades permite desvelar argumentos ideológicos que muitas vezes naturalizam os fenômenos históricos que permeiam os discursos e corroboram o atual resgate de um modelo específico de empreendedor, elegendo a empresa capitalista contemporânea como centro do processo socioeconômico de geração de riqueza, de renda e de trabalho. Como resultado da pesquisa, sugere-se que a (re)produção de discursos sob a lógica do sistema de mercado permite que, nos dias de hoje, a ideia de empreendedorismo desempenhe papel primordial na sociedade: assegurar que cada indivíduo assuma, como suas, as metas de reprodução do sistema capitalista. Por essa mesma razão, tal processo se distancia da busca pela emancipação e, ao contrário, promove modelos opressivos de comportamentos individuais destinados, em conjunto, a trabalhar ideologicamente para o alcance dos objetivos do capital.

Palavras-chave: empreendedorismo; empreendedor; perspectiva histórica; estudos organizacionais; discursos.

\begin{abstract}
This theoretical essay, through a historical perspective in organizational studies, seeks to identify and discuss the discursive appropriation of the idea of entrepreneurship at three different times: (a) in the classical period of the formation of capitalism; (b) in monopolistic capitalism; and (c) in current capitalism. As the discourses are not neutral, the identification of these discontinuities enable the unveiling of ideological arguments that often naturalize historical phenomena that permeate the discourses, corroborate the current resuscitation of a specific entrepreneur model and opt for the contemporary capitalist company as the central point of the process of the generation of wealth, income and employment in society. The results suggest that the (re)production of discourses in the logic of the market system nowadays allows the idea of entrepreneurship to have an important role in society: to ensure that every individual accepts as his own the goals of reproduction of the capitalist system. For this reason, this process moves away from the quest for emancipation and, instead, promotes oppressive models of individual behavior through appropriate expectations and specific forms of conduct.
\end{abstract}

Key words: entrepreneurship; entrepreneur; historical perspective; organizational studies; discourse. 


\section{Introdução}

Este trabalho tem por objetivo identificar e discutir diferentes apropriações da ideia de empreendedorismo ao longo da história por meio dos discursos acerca do empreendedor e de seu papel na sociedade capitalista ocidental. Quatro assunções embasam a argumentação aqui defendida ( $c f$. Fairclough, 2001; Foucault, 2007). Em primeiro lugar, a ideia de que os discursos não apenas refletem as relações sociais, mas antes as constroem. Em seguida, a posição de que o discurso não é apenas o que traduz as lutas ou os sistemas de dominação, mas aquilo pelo que se luta. Terceiro, a noção de que nenhuma linguagem é neutra, e que determinados usos da linguagem e de outras formas simbólicas são ideológicos, ou seja, estabelecem e mantêm, em circunstâncias específicas, relações de poder e dominação. Por fim, a proposição de que as tentativas de definir a direção da mudança cada vez mais incluem tentativas de mudar as práticas de linguagem. Tomando-se as quatro assunções em conjunto, assume-se neste estudo que a identificação de descontinuidades discursivas permite desvelar argumentos ideológicos que naturalizam fenômenos históricos e encobrem efeitos deletérios do entendimento atual acerca do tema do empreendedorismo.

Apelos ao incremento de possíveis contribuições acadêmicas da perspectiva histórica ao campo de estudos organizacionais vêm sendo registrados há pelo menos duas décadas (Goldman, 1994; Kieser, 1994; Zald, 1993), tendo sido recentemente intensificados (Booth \& Rowlinson, 2006; Clark \& Rowlinson, 2004; Costea, Crump, \& Holm, 2006; Curado, 2001; Jacques, 2006; Maielli, 2007; Maielli \& Booth, 2008; Tuchman, 1994; Üsdiken \& Kieser, 2004). Tais debates giram em torno dos limites e das possibilidades da pesquisa histórica, inseridos no contexto maior da produção de conhecimento no campo. Vizeu (2007, 2010), por exemplo, assevera que a incorporação da perspectiva histórica pode contribuir para o avanço na análise do fenômeno administrativo por meio do enriquecimento e da ampliação das pesquisas, tanto em função da adoção de um quadro teóricoconceitual, constituído a partir da análise histórica, quanto pela aplicação da pesquisa histórica como método de análise.

Ainda que as organizações tenham sido racionalmente projetadas para resolver conflitos entre as necessidades coletivas e as vontades individuais (Reed, 1999), seu processo de ação e criação necessariamente foi realizado por indivíduos em contexto histórico específico. Perscrutar esse contexto por meio de um quadro teórico-conceitual constituído a partir de uma perspectiva histórica torna possível ao pesquisador evitar o caráter anistórico e determinístico de alguns estudos (Zeitlin, 2008).

Em consonância com Rowlinson, Jacques e Booth (2009), pode-se observar uma predominância de orientação anistórica nas contribuições do mainstream à área de estudos organizacionais, provocando distorções metodológicas, distanciando acontecimentos e sublinhando uma intemporalidade universal. Tal é o caso, por exemplo, dos anacronismos, isto é, do uso de conceitos e ideias de uma época para analisar fatos de outro tempo histórico. Questionar essa intemporalidade é importante porque, ao proceder desta forma, o pesquisador põe em xeque a visão de organizações como unidades independentes e autônomas, que podem prescindir de avaliação moral ou de debates políticos (Reed, 1999). Ao mesmo tempo, a pesquisa histórica contribui para desnaturalizar ideias e conceitos vinculados às organizações e aos indivíduos nas organizações, desvelando discursos hegemônicos e formações ideológicas, como é o caso do tema empreendedorismo. Em última instância, a perspectiva histórica torna possível, outrossim, a compreensão de como a presente ordem foi construída e como ela pode ser modificada (Rowlinson, Jacques, \& Booth, 2009).

Desenvolvido como ensaio teórico (Nascimento, Feitosa, Marcon, Verdu, \& Bandeira-de-Mello, 2007), o presente artigo foi estruturado em quatro seções, além desta introdução e das considerações finais. A primeira seção traça uma contextualização do problema, por meio da qual se estabelece uma discussão crítica acerca de como as sucessivas construções discursivas ao longo da história deixam de questionar o constructo do empreendedorismo, especialmente por não discutir seu ideário a partir das relações de trabalho. As três seções subsequentes apresentam os diferentes contextos históricos, em 
que são identificadas rupturas em relação ao discurso acerca do empreendedorismo, e que são caracterizados como: (a) o empreendedor no período clássico de formação do capitalismo; (b) o empreendedor no capitalismo monopolista; e (c) o empreendedor no capitalismo atual.

\section{Problematizando o empreendedorismo a partir de uma perspectiva histórica}

O conceito de empreendedorismo - bem como seus desdobramentos teóricos e práticos - vem sendo valorizado por governos, entidades de classe e organizações como a principal base para o crescimento econômico e para a geração de emprego e renda na atualidade (Barros \& Passos, 2000; Barros \& Pereira, 2008). Considerando a iniciativa empreendedora como veículo ideal para inovar, aumentar a produtividade e melhorar modelos de negócios (Drucker, 1970), alguns autores arriscam-se a afirmar que estamos vivendo a era do empreendedorismo (Aidar, 2007; Dornelas, 2008), a substituição do homo economicus pelo homo attentaturus (Boava \& Macedo, 2009) ou testemunhando o alvorecer de um capitalismo empreendedor (Schramm \& Litan, 2008). Nesse contexto, subsiste a crença de que os empreendedores estão "eliminando barreiras comerciais, e culturais, encurtando distâncias, globalizando e renovando os conceitos econômicos, criando novas relações de trabalho e novos empregos, quebrando paradigmas e gerando riqueza para a sociedade" (Dornelas, 2008, p. 6).

Tal movimento, contudo, não vem acompanhado por um proporcional aumento nas pesquisas acadêmicas acerca do tema; pelo contrário, o que se pode identificar são "décadas de estudos inconclusivos e teoricamente pouco embasados" (Tasic \& Andreassi, 2007, p. 2). E tanto no que diz respeito aos estudos que buscam corroborar a influência do empreendedorismo no processo de crescimento e desenvolvimento socioeconômico dos países (Fontenele, 2009; Fontenele, Moura, \& Leocádio, 2010) quanto no que se refere aos estudos mais críticos em relação ao tema (Leite \& Melo, 2008; Ogbor, 2000).

De forma mais geral, alguns autores defendem a ideia de que não existe consenso em relação ao tema do empreendedorismo (Boava \& Macedo, 2009; Colbari, 2007), e que dar início a uma pesquisa sobre o assunto pode ser entendido como semelhante a entrar em "um bazar", no qual "encontra-se de tudo, para todos" (Filion, 1999, p. 8). De forma análoga, o rótulo de empreendedor pode constituir um significante vazio,

uma palavra que pode significar tudo e nada, uma palavra que não tem um significado intrínseco, não tem ... relação com nenhum dos objetos com os quais é normalmente associada, que remete a vários pontos sem chegar efetivamente a nenhum deles (Walker, 1989, p. 164).

Essa condição é bastante conveniente para naturalizar processos e fenômenos, já que o conceito pode assumir diferentes significados dependendo de seu contexto e uso. No entanto, mesmo em meio a tanta diversidade, de forma bastante genérica, pode-se identificar três abordagens mais recorrentes.

A primeira abordagem deriva de uma perspectiva de base behaviorista ou comportamental e concentra-se nas tentativas de definição dos perfis das personalidades do empreendedor e em compreender seu comportamento (Borges \& Casado, 2009; Kets de Vries, 1977). De acordo com Filion (1999), dos anos 1970 aos anos 1980 foram os behavioristas que dominaram a área do empreendedorismo, em grande parte em função dos trabalhos de David McClelland (1961, 1972) e dos avanços nas ciências do comportamento.

A segunda é uma abordagem mais ampla da literatura gerencial e concentra-se em estudos sobre as habilidades e competências empreendedoras e sua relação com o espaço organizacional. Segundo Mello, Leão e Paiva (2006, p. 48), estas competências relacionam-se "ao senso de identificação de oportunidades, à capacidade de relacionamento em rede, às habilidades conceituais, à capacidade de gestão, à facilidade de leitura, ao posicionamento em cenários conjunturais e ao comprometimento com interesses individuais e da organização". Como exemplo, pode-se destacar as pesquisas acerca do empreendedorismo institucional (Garud, Hardy, \& Maguire, 2007); dos empreendedores como produtos organizacionais (Audia \& Rider, 2006); do empreendedorismo social (Parkinson \& Howorth, 2007; Sousa, Oliveira, Fagundes, Dami, \& Lima, 2005), coletivo (Rodrigues \& Malo, 2006) e 
sustentável (Boszczowski \& Teixeira, 2009) e do intraempreendedorismo (Chieh \& Andreassi, 2007). Ainda no que concerne a essa abordagem, várias correntes teóricas são contempladas, englobando pesquisas referentes a temas como: (a) empreendedorismo como fomento tecnológico, criando, desenvolvendo e gerenciando empresas emergentes; (b) empreendedorismo como gestão (difusão da prática da gestão empreendedora); e (c) empreendedorismo como estratégia de desenvolvimento local integrado e sustentável, por meio do desenvolvimento de micros, pequenas e médias empresas.

A terceira e última abordagem - alinhada à perspectiva de base econômica acerca do empreendedorismo - concentra-se nas relações entre o tema e as ideias de inovação, risco calculado e desenvolvimento. $\mathrm{O}$ destaque para a questão do caráter inovador continua em definições mais atuais, que privilegiam novas oportunidades de investimento, de produto ou de negócios (Bygrave \& Hofer, 1991; Krueger \& Brazeal, 1994) ou a criação de novas empresas (Gartner, 1989).

Ainda que desenvolvidas sob diferentes prismas, as três abordagens convergem para o mesmo ponto: para que uma sociedade fundamentada em um mercado livre seja capaz de produzir mais riqueza, torna-se premente a existência de indivíduos capazes de criar e aproveitar oportunidades, melhorar processos e inventar negócios. De que adiantaria um mercado livre sem tal espírito empreendedor? Dito de outra maneira, o atual processo de valorização, celebração e exaltação do empreendedor e do empreendedorismo privilegia um modelo específico de desenvolvimento econômico e social pautado pelo capitalismo de mercado, assumido como natural, ideal e exemplar. A partir dessa ótica, para que uma sociedade possa potenciar todos os supostos benefícios provenientes de um mercado livre capitalista, necessita do espírito empreendedor gerador de inovação e de riquezas.

Nesse sentido, nos dias de hoje a busca incessante do ganho é mais do que uma obrigação e o indivíduo passa a ser qualificado como o sujeito econômico capitalista por excelência (Lemos, 2005). Inseridos nessa lógica, os empreendedores são concebidos como indivíduos que impulsionam a máquina capitalista, ao prover novos bens de consumo, além de métodos inovadores de produção e transporte, com a inequívoca função social de identificar oportunidades e convertê-las em valores econômicos. Desta feita, o empreendedorismo apresenta-se como fundamental para o desenvolvimento econômico, potenciando lucros por intermédio de uma "visão" ou um "espírito" muitas vezes mais pessoal do que coletivo. Leite e Melo (2008, p. 36), por exemplo, destacam que as atuais ferramentas organizacionais substituem os esquemas coletivos de segurança financeira, de saúde e profissionais percebidos como 'antigos' e o que passa a contar é "o indivíduo - suas realizações, seu capital social bem ampliado, pronto para ser usado profissionalmente, tanto no próprio trabalho, quanto para arrumar outros".

Nesse processo discursivo, entretanto, não são questionadas as implicações para as relações de trabalho contemporâneas da (re)produção da ideia de empreendedorismo. Naturaliza-se a premissa de que o profissional contemporâneo é uma unidade econômica autônoma inserida em um contexto competitivo, sendo o "eu empreendedor ... um atributo fundamental do indivíduo empregável, que precisa empenhar-se na autogestão da sua carreira, deve ser empresário de si próprio e ver a si mesmo como se fosse um negócio" (Lemos \& Rodrigues, 2008, p. 2). Segundo Boava e Macedo (2009, p. 3), o empreendedorismo passa a representar um "tipo particular de sistemas de ideias com verdades, crenças, tradições, princípios, finalidades e mitos próprios" sustentado - de forma não tão transparente - por interesses de determinados grupos sociais.

É neste sentido que Boltanski e Chiapello (2009) argumentam ser o empreendedorismo uma ideologia do novo espírito do atual capitalismo, onde um conjunto de crenças dirige, justifica e legitima o comprometimento dos indivíduos com o sistema. Esse novo ethos do empreendedorismo dissemina uma visão de mundo que busca padrões organizacionais tanto de produção flexível quanto de novos arranjos sociais fora das relações salariais tradicionais (Colbari, 2007). Cabe ressaltar que tal comprometimento quase nunca apresenta chances reais e efetivas de obtenção de algum lucro ou ganho substancial por parte dos indivíduos. Pelo contrário, tal construção torna-se importante exatamente porque, de várias formas, o capitalismo se apresenta como um 'sistema absurdo' (Chiapello \& Fairclough, 2002). A partir dessa lógica, nada se pronuncia a respeito do contexto histórico das atuais condições de trabalho, das relações de poder inerentes a esse contexto, da 
precarização que acompanha a vida profissional da maior parte dos empreendedores e de qual modelo de trabalhador o conceito de empreendedorismo privilegia.

É no intuito de tentar romper com perspectivas hegemônicas, exclusivistas e determinísticas assim como aquelas associadas ao constructo do empreendedorismo - que a contribuição da pesquisa histórica em estudos organizacionais adquire relevância. A ideia é contribuir com: (a) a promoção do resgate dos aspectos históricos e interculturais que deveriam direcionar os estudos nestas áreas em oposição à reprodução ideológica dominante, que tende a excluir o passado ou o contexto das teorias e do agir organizacional; e (b) a aproximação dos pesquisadores aos contextos nos quais estão insertos, mais especificamente a seus mecanismos de constituição. Tal comprometimento pode potenciar uma posição de engajamento ou de compromisso consciente do pesquisador com seu contexto, transcendendo, ao mesmo tempo, a condição de simples copista e repetidor de teorias, e a atitude ingênua de crença em uma ciência imune a condicionamentos (Guerreiro Ramos, 1996). Para Benjamin (1994), o estudo da história é o maior antídoto contra o conformismo ideológico.

\section{O empreendedor no período clássico de formação do capitalismo}

Apesar das dificuldades inerentes ao estabelecimento de marcos históricos - em particular no que se refere ao fenômeno do capitalismo - Falcon e Moura (1989) argumentam que os limites cronológicos do período de formação do capitalismo (ascensão e estabelecimento das formas capitalistas da sociedade liberal) podem ser estabelecidos entre os anos de 1760/80 a 1870/80. Note-se que na presente pesquisa se assume a ideia de capitalismo como vinculada a um conjunto de comportamentos individuais e coletivos em relação à produção, à distribuição e ao consumo dos bens. Segundo Rusconi (1992), a partir de tais comportamentos, é possível destacar características que distinguem o capitalismo de outros modos históricos de produção, quais sejam: (a) existência de propriedade privada dos meios de produção, para cuja efetivação se torna necessário o trabalho formal assalariado e livre; (b) sistema de mercado baseado na iniciativa e na empresa privada; e (c) processos de racionalização dos meios e métodos diretos e indiretos para a valorização do capital e a exploração das oportunidades de mercado para efeito de lucro.

O período de formação do capitalismo ocorre concomitantemente com o fenômeno da Revolução Industrial, que se inicia na Grã-Bretanha na segunda metade do século XVIII; na França e nos Estados Unidos, a partir dos primeiros anos do século XIX; na Alemanha, apenas nas últimas décadas desse mesmo século. Tal momento histórico pode ser caracterizado por grande expansão nas atividades comerciais, empresariais e manufatureiras, assumindo os países mais representativos deste processo a posição de modelo a ser seguido. Em outras palavras, o poder das nações associava-se ao progresso econômico e era exemplar: "todos os governos continentais com qualquer pretensão a uma política racional estavam conseqüentemente fomentando o crescimento econômico e especialmente o desenvolvimento industrial" (Hobsbawn, 1989, p. 36).

Foi em tal contexto que, na segunda metade do século XVIII, Richard Cantillon (1755/1950) fez um esforço no sentido de tentar identificar quem era o indivíduo empreendedor, vinculando sua representação não em relação à sua função na sociedade, mas a seu posicionamento com respeito ao risco das oscilações de oferta e demanda. Esse indivíduo - o empresário - poderia ser tanto o comerciante, quanto o artesão/produtor de manufatura ou o colono agricultor. Para Filion (1999, p. 4), em contexto de revolução industrial, o interesse de Cantillon pelos empreendedores não era um fenômeno isolado, sendo antes harmônico com as ideias dos pensadores liberais da época, que "exigiam ... liberdade plena para que cada um pudesse tirar o melhor proveito dos frutos de seu trabalho".

De acordo com Cantillon (1755/1950), o colono caracterizava-se como empresário, uma vez que prometia pagar ao proprietário de suas terras uma soma fixa de dinheiro, de forma que lhe fosse permitido explorá-la, sem ter a certeza do benefício que poderia obter deste empreendimento. Também poderia ser tido como empresário o comerciante que levava os produtos do campo para as cidades, pagando um preço certo de acordo com o lugar onde comprava as mercadorias e revendendo-as por 
um preço incerto - pois jamais poderia saber qual seria o volume de consumo em sua cidade nem quanto tempo seus clientes seguiriam adquirindo seus produtos. Por último, a mesma lógica se aplicava ao artesão que comprava do comerciante e do produtor o que necessitava para produzir, mas não tinha garantias do que seria obtido por meio da venda de seus produtos.

Outro importante economista liberal que ressaltou uma função especial para o empreendedor na sociedade foi Jean Baptiste Say ( $c f$. Schumpeter, 1924/1968). Para Say (1803/1983), o empreendedor é o empresário, que se posiciona no centro do processo econômico de forma a equilibrá-lo, assumindo o papel de intermediário entre as classes de produtores, e entre os produtores e os consumidores. Esse empresário administraria a obra da produção, apresentando-se como o eixo de várias relações. Para tanto, ser empresário requereria "tino, constância e conhecimento dos homens e das coisas", uma vez que este teria de "avaliar adequadamente a importância de determinado produto, a necessidade que dele haverá e os seus meios de produção; trata-se, às vezes, de pôr em jogo um grande número de indivíduos" (Say, 1803/1983, pp. 312-313). Para Say (1803/1983, pp. 312-313), o empresário teria como incumbências "comprar ou fazer comprar matérias-primas, reunir operários, procurar consumidores, ter espírito de ordem e de economia; numa palavra, é preciso ter o talento de administrar". Ainda nas palavras do economista: "as pessoas em quem não se encontram reunidas as qualidades necessárias promovem empresas com pouco êxito ... assim, a condição da capacidade limita o número de pessoas que oferecem o trabalho de empresário" (Say, 1803/1983, p. 313).

Assim, o empresário de Say é um agente econômico racional e dinâmico que age num universo de certezas. Ele procura alcançar o equilíbrio financeiro de sua empresa e o máximo de lucro e de vendas, esforçando-se por adaptar sua produção às necessidades crescentes. Mediante este processo, o empresário - ao satisfazer seu interesse pessoal - torna-se capaz de promover o equilíbrio do sistema econômico (Tapinos, 1983). Apregoa-se, destarte, uma atitude liberal, dando origem à sociedade econômica, em que se privilegia o interesse privado e onde o Estado se afasta de qualquer intervenção capaz de deturpar a concorrência: para Say "não existem obstáculos insuperáveis para o desenvolvimento. Não existem limites para o enriquecimento de uma nação ... o bem-estar de um país depende da sua população ativa, do progresso técnico, do dinamismo de seus empresários" (Say, 1983, p. 31).

Um terceiro economista que buscou entender quem era o empreendedor, bem como sua função na sociedade, foi Werner Sombart, por meio de suas obras "A gênese do capitalismo moderno" (1902/1946) e "O burguês" (1903/1953). Para Sombart (1902/1946), cada época reflete atitudes diferentes em relação à atividade econômica: na época específica em que centra a sua análise - o capitalismo de final do século XVII ao início do século XX - o sujeito econômico capitalista é o empresário capitalista, e a sua função consiste em unificar o capital e o trabalho, determinar a direção e o volume da produção e estabelecer a relação entre produção e consumo.

No parecer de Sombart (1902/1946), tal sujeito econômico diferencia-se do empreendedor dos primórdios do capitalismo - muito embora este tenha sido obra de uns poucos homens de negócios empreendedores provenientes de camadas diversas da população - uma vez que esses precursores não tinham força suficiente para dirigir a vida econômica em seu conjunto. Durante o apogeu do capitalismo, porém, os únicos organizadores do processo econômico predominante passam a ser os empresários. Cabe ressaltar que, para Sombart (1902/1946), nem todos os indivíduos podem ser este sujeito econômico do capitalismo. $\mathrm{O}$ autor assevera que somente alguns podem exercer a função de organizar o processo econômico: aqueles possuídos pela paixão de ganhar dinheiro - afã do lucro cujo principal motor é o impulso lucrativo, e que têm na ganância seu motivo determinante.

Para Sombart (1902/1946) existem três tipos de empresários: (a) o inventor-empresário, cuja preocupação é com a organização da exploração industrial de seu produto (captain of industry); (b) o comerciante, caracterizado como o homem de negócios preocupado com a demanda do mercado (business man); e (c) o empresário-financeiro, cuja preocupação é com o capital (corporation financier). Os três tipos, no entanto, misturam-se no dia-a-dia e adquirem maior ou menor importância conforme as atividades capitalistas se vão modificando. Lodi (2002, p. 7), por exemplo, propondo-se a rever a história da administração, atribui a tais indivíduos a pecha de "poderosos capitães", 
denominação reservada para "um homem sozinho com grande energia e inteligência [que] poderia controlar tudo sozinho do alto da organização".

Cabe ressaltar dois últimos pontos com relação ao entendimento de Sombart (1902/1946) acerca de quem seria o empreendedor. Um primeiro ponto refere-se à ênfase que o autor atribuía à figura do empresário de sucesso e a seu exemplo para toda a sociedade. A partir das biografias de homens tais como Alfred Krupp, Werner Siemens, Robert Bosch, Emil Rathenau, Felix Deutsch e Henry Ford, uma imagem mítica sobre o empreendedor começa a ser construída. Um segundo ponto diz respeito à sua identificação de um processo de dissociação entre o empresário e o possuidor de capital. Tal processo ocorre, concomitantemente, a dois outros processos, a saber: (a) a evolução da empresa privada em direção às sociedade anônimas; e (b) a transformação do proprietário-empresário em empregado-dirigente.

Diante de tantas ideias acerca do empreendedor e de sua função, entretanto, a definição resgatada e mais utilizada na atualidade acerca do empreendedorismo é aquela extraída da obra do economista Joseph Schumpeter. Em seus escritos dos anos 1910 e 1920, o empreendedor é compreendido, sobretudo, como sujeito inovador que impulsiona o desenvolvimento econômico e social por intermédio da reforma ou da revolução nos padrões de produção. Em consonância com Castanhar (2007), pode-se argumentar que foi esse economista que firmou o caminho para uma linha de investigação sobre a relação entre empreendedor e o desenvolvimento econômico.

Para Schumpeter, o processo de desenvolvimento não pode ser entendido como mero crescimento da economia (passível de demonstração por meio do crescimento da população e da riqueza), mas antes como um fenômeno diferente do que pode ser observado no fluxo circular ou na tendência para o equilíbrio: apresenta-se como "mudança espontânea e descontínua nos canais do fluxo, perturbação do equilíbrio, que altera e desloca para sempre o estado de equilíbrio previamente existente" (Schumpeter, 1911/1982 p. 47).

Essas mudanças espontâneas e descontínuas aparecem na esfera da vida industrial e comercial, e não na esfera das necessidades dos consumidores, sendo "o produtor que, via de regra, inicia a mudança econômica" (Schumpeter, 1911/1982, p. 48). Assim, "a função empresarial é não apenas o veículo de contínua reorganização do sistema econômico, mas também o veículo de mudanças contínuas" (Schumpeter, 1911/1982, p. 104), sendo o processo de desenvolvimento econômico (e seus ciclos) decorrência do surgimento de novas combinações e novos usos de recursos: (a) introdução de um novo bem ou de um bem já existente com nova característica; (b) introdução de novo método de produção; (c) abertura de novo mercado; (d) descoberta de novas fontes de suprimento; e (e) desenvolvimento de novas formas de organização.

Tais inovações apresentam-se como potenciadoras de desequilíbrios (ou perturbações) que movimentariam as economias e as sociedades em direção ao desenvolvimento. Assim, o empreendedor é o agente que inicia estas mudanças, alterando o sistema em equilíbrio por meio da identificação de novas oportunidades: "chamamos 'empreendimento' a realização de combinações novas; chamamos de 'empresários' os indivíduos cuja função é realizá-las” (Schumpeter, 1911/1982, p. 54).

Cabe ressaltar que a imagem do empreendedor como empresário e/ou como capitalista provedor do desenvolvimento econômico era uma representação recorrente na época em análise, fosse tal imagem positiva ou negativa. Por exemplo, posicionando-se de forma contrária aos pensadores liberais, Karl Marx destacou, de outra forma, a importância dos capitalistas modernos - proprietários dos meios de produção (burguesia) - que devem a sua existência à condição de "revolucionar incessantemente os instrumentos de produção, por conseguinte, as relações de produção e, com isso, todas as relações sociais" (Marx \& Engels, 1848/1980, p. 12). Para Marx, esses agentes seriam os responsáveis pela condição de subversão contínua do sistema social e a sua permanente instabilidade ou falta de segurança. 


\section{O empreendedor no capitalismo monopolista}

Os períodos entre 1870/80 e 1914/18 podem ser compreendidos como momentos de expansão da sociedade liberal e apogeu do liberalismo - em termos políticos e de visão de mundo. Segundo Hobsbawn (1988, p. 22), trata-se de dois períodos em que ocorre o avanço da economia capitalista em escala mundial e "da ordem social que a representa, das ideias e credos que pareciam legitimá-lo e ratificá-lo: na razão, ciência, progresso".

A partir de tais momentos, registra-se o surgimento de importantes mudanças: (a) o surgimento das grandes empresas; (b) a tendência à monopolização associada à concentração de capital a partir de oligopólios, em que o grande capitalista tende a suplantar ou reduzir à dependência os pequenos e médios capitalistas; (c) políticas econômicas de caráter deliberadamente protecionista; (d) projeção imperialista (impulso colonial que promoveu a partilha do mundo); (e) advento da democracia liberal; e (f) aumento das rivalidades internacionais (Falcon \& Moura, 1989).

Tais mudanças intensificam-se no decorrer das décadas seguintes e, neste novo momento do capitalismo, agora de tendência monopolista, o papel dos empreendedores é alterado. No parecer de Cardoso (1964), eles não mais desempenham as funções empresariais apenas quando criam novas combinações, uma vez que, nas atividades econômicas modernas, a continuidade da organização se apresenta como fundamental para seu êxito. No contexto de formação das grandes sociedades anônimas, a "burocratização das organizações econômicas modernas, a complexidade do mercado nas economias altamente desenvolvidas ... e as condições de realização do lucro impuseram uma redefinição das funções empresariais" (Cardoso, 1964, p. 24).

Assim, nessa nova configuração do capitalismo, os empresários tipificados por Sombart (1902/1946) serão empresários "mais na medida em que forem capazes de por em prática técnicas que assegurem vantagem econômica, do que na medida em que forem capazes de inventar práticas comerciais, financeiras ou de produção" (Cardoso, 1964, p. 24). Dito de outra forma, o êxito do empreendedor não se resumiria na sua aptidão criadora, mas na continuidade efetiva que for capaz de imprimir à nova combinação econômica implantada. Mais especificamente, as sociedades por ações redefinem o modo de produção capitalista, modificando a ideia de capital como propriedade e direção personalizadas, uma vez que, mediante a "concentração da produção em grandes unidades, as inovações predominam a tal ponto que o chamado 'talento empresarial' tornou-se obsoleto, não havendo mais espaço para capitalistas individuais" (Tragtenberg, 2005, p. 19).

Em tal contexto, a ideia de inovação passa a ser vinculada à capacidade de controlar o conjunto de resultados de uma alteração proposta, tanto no nível da empresa como nos níveis da ordem econômica e da ordem social global, independentemente de tais procedimentos se apresentarem como resultado da imaginação de empresários-proprietários ou de administradores profissionais. Na empresa altamente burocratizada do capitalismo contemporâneo, "a inovação depende, portanto, muito mais dos mecanismos de decisão em função do conjunto dos fatos sociais, do que das qualidades pessoais de um empreendedor de talento inventivo", sendo que "a empresa, não o empreendedor, constitui o sujeito do processo econômico" (Cardoso, 1964, p. 27).

Cabe ressaltar que as funções empresariais são mantidas na economia moderna. Seu papel, contudo, é alterado. Na época das grandes sociedades anônimas, consórcios, cartéis, bem como a economia são, cada vez mais, políticas, porque o que passa adquirir importância são outros fatores, a saber: (a) a formação de grupos de pressão nas empresas; (b) o poder de decisão alcançado por intermédio das alianças que se formam nas assembléias de acionistas; (c) as alianças entre grupos econômicos; e (d) o surgimento na cena econômica de nova personagem para garantir a prosperidade, o Estado (Cardoso, 1964).

Na nova conjuntura, a decisão econômica torna-se decisão total - econômica, política e social que, para ser posta em prática, irá depender da persuasão, do jogo de influências e da imposição (e não simplesmente da aquisição dos meios a serem combinados para produzir uma inovação). O número cada vez maior de grandes empresas formaria um contexto de agravamento das crises periódicas do 
sistema e de consequente intensificação da concorrência entre os produtores pelos mercados internos e externos (Falcon \& Moura, 1989). A livre concorrência e a livre determinação dos preços pelas leis da oferta e da procura foram sendo relegadas a um plano secundário, uma vez que o capitalismo se tornou cada vez menos livre, tal a capacidade de intervenção nas condições de funcionamento do mercado detidas pelo grande capital e pelo Estado. Cabe recordar que as práticas protecionistas são resgatadas neste momento, porém com características diferentes: as grandes empresas buscavam subsídios do governo como forma de auxílio à conquista de mercados estrangeiros.

De acordo com Rusconi (1992), muitas das características supramencionadas apareceram durante o primeiro conflito mundial e foram testadas nos anos subsequentes. No entanto, somente nos anos 1930 (contexto da crise de 1929), gradualmente foram elas configurando-se mediante o processo de concentração das grandes empresas, a organização cada vez mais rígida dos mercados de bens, de capitais e de trabalho, e a sistemática intervenção do Estado na economia. Portanto,

os sistemas econômicos 'mistos', caracterizados pela presença estatal direta (por meio da empresa pública) e indireta (pelos institutos de co-participação e controle estatal), não são mais fenômenos anômalos ou típicos de economias atrasadas em relação aos modelos do capitalismo avançado (Rusconi, 1992, p. 145).

Cabe ressaltar que o Estado se limita - na maior parte das vezes - a substituir as regras tradicionais do mercado, mantendo as condições de sua reprodução. Desta feita, também na fase liberal do capitalismo, o Estado garantia a reprodução e o funcionamento do sistema econômico por meio de funções específicas, como

a defesa dos direitos privados da empresa e adequação do aparelho legislativo às necessidades surgidas ... durante o desenvolvimento econômico; a defesa da força-trabalho contra a lógica da indiscriminada exploração capitalista (legislação social) e, mais geral, criação de infraestruturas para a reprodução da força-trabalho (transporte, escolarização, urbanização etc.) (Rusconi, 1992, p. 146)

O próprio Schumpeter, a partir dos anos 1930, redefine suas ideias, ao defender a tese de que a competição perfeita raramente havia existido na história, e que não havia motivos para considerá-la no longo termo - como modelo de eficiência na promoção do crescimento econômico. Segundo esse autor,

o impulso fundamental que põe e mantém em funcionamento a máquina capitalista procede de novos bens de consumo, dos novos métodos de produção ou transporte, dos novos mercados e das novas formas de organização industrial criadas pela empresa capitalista (Schumpeter, 1961/1942, p. 105).

Desta forma, por meio do deslocamento do indivíduo empreendedor para o indivíduo coletivo, seriam as grandes empresas, e não mais os indivíduos, os principais agentes promovedores dos processos de destruição criadora que impulsionam o capitalismo.

\section{O empreendedor no capitalismo atual}

Nos dias de hoje, que valores orientam a conduta dos indivíduos, possibilitando que o sistema econômico continue seu desenvolvimento? Reformulando a questão, que valores permitem, no início do século XXI, manter o capitalismo em funcionamento, acelerando e intensificando seus processos?

Um primeiro ponto a ser destacado diz respeito ao paradigma econômico e político que fundamenta o capitalismo na atualidade: o neoliberalismo. Diante das crises iniciadas nos anos 1970 e de um diagnóstico que associava a estagnação econômica do período ao excesso de regulamentações, o Consenso de Washington ocorreu no início dos anos 1980, elaborado pelos países centrais do sistema mundial, "abrangendo o futuro da economia mundial, as políticas de desenvolvimento e especificamente o papel do Estado na economia" (B. Santos, 2002, p. 33). Este consiste em um 
conjunto de políticas e processos que caracteriza o capitalismo nos dias de hoje e expressa o fim de um ciclo longo expansivo com base nas grandes corporações internacionais, apoiadas em sistema financeiro em expansão e no Estado de bem-estar social que promovia: (a) investimentos produtivos; (b) fortalecimento da demanda interna de consumo; (c) papel regulador dos Estados; e (d) proteção das respectivas economias (Sader, 2008).

Simultaneamente, as principais inovações institucionais desse processo foram: (a) restrições à regulação estatal da economia; (b) novos direitos de propriedade internacional para investidores estrangeiros, inventores e criadores de inovações; e (c) subordinação dos Estados nacionais às agências multilaterais, tais como Banco Mundial, Fundo Monetário Internacional e Organização Mundial do Comércio (B. Santos, 2002). Assim, as soluções foram centralizadas em projetos de desregulamentação por meio de privatizações, da liberalização do mercado e do sistema financeiro, da abertura das economias dos países para o mercado externo, de políticas de flexibilização laboral e de ajuste fiscal (Belluzzo, 2005; Chomsky, 2002; Sader, 2008). Especificamente com relação à flexibilização laboral, B. Santos (2002, p. 40) argumenta que "o consenso neoliberal é o de que o crescimento e a estabilidade econômica assentam na redução dos custos salariais, para o que é necessário liberalizar o mercado de trabalho, reduzindo os direitos laborais".

López-Ruiz (2007) argumenta que essas questões se relacionam com o resgate da figura do empreendedor e de sua função social, com inspiração no sujeito econômico dos primórdios do capitalismo. Em sua opinião, a conduta exemplar voltou a ser aquela do empreendedor, e não ocorre apenas no plano estritamente econômico por meio da disseminação de uma forma empresarial modelo. Para L. Santos (2007, p. 21),

o empreendedor deve exercer o seu papel o tempo todo, em qualquer lugar, mais ainda: já que a cidade, a comunidade, a ONG, o casal e até ele próprio devem ser vistos como uma empresa, das duas uma: ou o mercado recobre a sociedade inteira ou esta se reduz à esfera econômica.

Burns e DeVille (2006, p. 24), em seu turno, lembram que "o capitalismo não é um empreendimento puramente econômico, mas também cultural e político".

O resgate do empreendedor, no entanto, não acontece de forma literal. Algumas alterações e releituras ocorreram em função do mundo atual ser, contextualmente, bastante diferente do mundo do final do século XIX. Uma primeira mudança refere-se à ideia de que o empreendedor deixa de ser figura rara: a doutrina neoliberal exige que todos se apresentem socialmente como empreendedores. Segundo López-Ruiz (2007, p. 30), "para a continuidade do desenvolvimento do capitalismo torna-se imprescindível o surgimento do empreendedorismo como fenômeno de massa", o que faz com que o empreendedorismo passe a ser uma atitude recomendada para os povos que buscam o crescimento e o desenvolvimento socioeconômico.

Uma segunda mudança desdobra-se a partir da primeira e se consubstancia no argumento de que o sistema econômico já não precisa de alguns poucos homens de negócios empreendedores, cuja função social seja promover o desenvolvimento econômico. Aquilo de que o sistema econômico necessita é de nova ética empresarial do trabalho:

um conjunto de valores e normas que seja compartilhado dentro de uma sociedade, a partir do qual quem trabalha seja levado a pensar e a sentir a sua atividade como uma empresa particular e como o principal motivo da sua vida (López-Ruiz, 2007, p. 30).

Essa nova ética do trabalho pressupõe, entre outros pontos, estreita ligação entre indivíduo e empresa. Tal movimento pode ser percebido, por exemplo, em abordagens mais atuais acerca do tema do empreendedorismo, por meio das quais os autores transferem para as empresas as características e habilidades do empreendedor, como no caso do modelo de Lumpkin e Dess (1996), cujas cinco dimensões (autonomia, capacidade de inovação, capacidade de assumir riscos, capacidade de agir proativamente e competitividade agressiva) se referem não aos empreendedores, porém à orientação empreendedora das organizações. Pode-se também perceber este movimento no deslocamento do foco do indivíduo para o grupo inserido em organizações, como destacam Vasconcelos, Mascarenhas e 
Kunda (2007, p. 2), ao chamar a atenção para a vinculação entre ampliação da capacidade empreendedora dos grupos e desenvolvimento socioeconômico, uma vez que "se até recentemente associava-se a capacidade empreendedora à qualificação formal de indivíduos, evidencia-se a crescente relevância de considerarmos processos interativos e cooperativos de aprendizagem, o que desloca a ênfase à capacitação local em inovação de forma coletiva e sistêmica".

Dessa maneira, apesar de ter adquirido maior visibilidade nas últimas duas décadas, pode-se argumentar que esse processo de valorização da ascensão socioeconômica de indivíduos empreendedores não é algo novo. O resgate dessa valorização e a exaltação de um 'espírito' empreendedor na atualidade são coerentes com a reformulação neoliberal da economia política contemporânea, na qual o espírito do capitalismo produz um repertório de explicações da realidade que toma a figura do executivo capitalista como matriz de conduta a ser disseminada pela sociedade inteira, fundada no investimento constante e exclusivo da vontade na produção da riqueza abstrata ( $c f$. López-Ruiz, 2007).

Tal matriz prolonga e intensifica a obrigação do homem moderno de dedicar sua vida ao ganho, reduzindo os atributos dos indivíduos à dimensão do interesse e incorporando a lógica do capital como fundamento existencial mais importante (L. Santos, 2007). Dentro dessa racionalidade, para que uma sociedade fundamentada em um mercado livre seja capaz de produzir mais riqueza, torna-se premente a existência de indivíduos capazes de criar e aproveitar oportunidades, melhorar processos e inventar negócios. Nesse sistema, quase todas as pessoas podem ser tidas como empreendedoras: o fundador de uma organização, o gerente de sua própria empresa, o líder que inova de uma organização de propriedade de outrem, ou qualquer pessoa que tome iniciativa estratégica dentro de uma organização, todos merecem por isso o rótulo de empreendedores internos (Mintzberg, Ahlatrand, \& Lampel, 2000).

Também o tema do empreendedorismo pode levar a uma reflexão acerca do julgamento moral que a sociedade faz da atividade empresarial. Para o senso comum brasileiro, o empresário parece um ser ganancioso, individualista e que só pensa em ganhar dinheiro, isto é,

aquele que empreende movido por interesse econômico é muitas vezes mal visto pela sociedade e pelos trabalhadores que emprega, que se sentem explorados pelo patrão ... em oposição à visão heróica do empreendedor norte-americano, a imagem do empresário brasileiro é associada à ganância e exploração (Lemos, 2005, p. 2).

Talvez esteja ocorrendo, na atualidade, uma releitura do juízo que se faz do empreendedor por meio de formações discursivas específicas, pois não parece claro para o senso comum se ser empreendedor no Brasil é bom ou ruim, se é um vício ou uma virtude.

Este movimento de ressignificação confunde-se, segundo Colbari (2007), com: (a) novos processos de socialização e qualificação para o trabalho; (b) os resultados pretendidos de uma reestruturação produtiva que reduz o considerado emprego padrão (registrado, formal e protegido); e (c) um projeto político alternativo ao trabalho assalariado. Assim, "a colonização do discurso pela economia e pela necessidade de inovação técnica faz com que os cidadãos se assujeitem ao ideário da inovação, da competitividade, do empreendedorismo" (Braga, 2006, p. 3). Ou, dito de outra maneira, o empreendedorismo promove uma cultura do trabalho "resignada diante do desemprego e adaptada ao risco, à insegurança e à incerteza ... dissociada do paradigma do mercado de trabalho formal" (Colbari, 2007, p. 100). Estas novas formas alternativas de inserção nas atividades produtivas convergem para o que Boltanski e Chiapello (2009, p. 58) destacam como sendo uma importante característica do capitalismo atual: a incorporação e disseminação de "um espírito que oferece perspectivas sedutoras e estimulantes de vida oferecendo ao mesmo tempo garantias de segurança e razões morais para se fazer o que se faz".

Neste sentido, a atual valorização do empreendedorismo parece apontar, nas palavras de Guerreiro Ramos (1996, p. 73), uma incorporação ingênua por parte dos indivíduos desse conceito, sem um fundamental "procedimento crítico-assimilativo da experiência estrangeira". Em outras 
palavras, o conceito é aceito, incorporado e disseminado no imaginário nacional sem releituras que incorporem o contexto social, econômico, político e cultural brasileiro. Curiosamente, quando se passa à instância prática, podem advir algumas surpresas. Segundo Barros e Pereira (2008, p. 989), por exemplo, recentes resultados de pesquisas empíricas indicam existir "uma associação negativa entre a atividade empreendedora por necessidade e o crescimento econômico" em países pobres - nos quais foi incluído o Brasil - enquanto somente nos "países relativamente ricos ... a atividade empreendedora associa-se positivamente com maior taxa de crescimento econômico".

Por último, deve-se ressaltar que o resgate do empreendedor não torna transparentes as idiossincrasias inerentes aos princípios neoliberais, nem as possíveis consequências econômicas de suas políticas. Apenas de forma a apontar algumas críticas a tais princípios, pode-se enfatizar o posicionamento de McChesney (2002), que destaca que tais políticas geram: (a) o crescimento da desigualdade econômica e social; (b) o aumento da pobreza absoluta entre as nações e povos mais atrasados do mundo; (c) um ambiente global catastrófico; (d) uma economia global instável; (e) e um enriquecimento acelerado para os já ricos. De forma complementar, B. Santos (2002) salienta os seguintes problemas: (f) aumento dramático das desigualdades entre os países ricos e os países pobres; (g) acirramento de tais desigualdades no interior de cada país, entre classes ricas e pobres; (h) catástrofes ambientais; (i) conflitos étnicos; (j) ocorrência de migrações internacionais massiva; (k) emergência de novos estados e a falência ou implosão de outros; (l) proliferação de guerras civis; (m) democracia formal como condição política para a assistência internacional. Por fim, Chomsky (2002) reforça os argumentos anteriores ressaltando os seguintes problemas: (n) debilitação da educação e da saúde; (o) aumento da desigualdade social; e (p) redução da parcela do trabalho na distribuição de renda.

\section{Considerações Finais}

Neste artigo, buscou-se argumentar em favor do aprofundamento da utilização da perspectiva histórica nos estudos organizacionais com o objetivo de contribuir para uma melhor compreensão acerca do conceito de empreendedor e de seu atual papel na sociedade.

Como argumenta Konder (2000, p. 97), "o sentido das teorias permanece incompleto e em muitos casos truncado, se não se leva em conta o uso histórico, o uso social, e em última análise também o uso político que é feito delas". E é isso que parece acontecer com o contemporâneo modelo neoliberal que, imposto pelas nações dominantes, parece ter alcançado um status de consenso, permitindo que a sua transposição para outras sociedades seja vista como natural, inevitável, desejada e benéfica. Em vista de tal condição hegemônica, dificilmente são aceitas considerações críticas ao modelo, mesmo porque estas críticas não costumam oferecer as tão (aparentemente) esperadas alternativas ao sistema. Levando-se em conta essa problemática, torna-se necessário e urgente o rompimento com essa ideia, uma vez que "é completamente impensável se sustentar a validade intemporal e a permanência de qualquer coisa historicamente construída" (Mészáros, 2008, p. 63).

A contextualização dos discursos adquire importância em face de tais questionamentos. Ao se apresentarem como forma de ação, os discursos não apenas refletem relações sociais, entidades-chaves ou sujeitos sociais, mas os constroem de diferentes formas (Fairclough, 2001). Como resultado, passam a ser fundamentais: (a) a compreensão das condições de produção do discurso, para que se possa identificar o sentido produzido; (b) a identificação do caráter utilitário do discurso; e (c) a aceitação de que o discurso possui intrinsecamente uma rede simbólica de relações de dominação ideológica e de poder (Phillips, Laurence, \& Hardy, 2004). Assim, a identificação da construção discursiva do empreendedor em diferentes contextos torna possível o questionamento de uma visão naturalizadora e anistórica acerca do empreendedorismo que, na atualidade, elege apenas uma possível configuração, como se esta ideia sempre tivesse existido da forma como existe nos dias de hoje: o papel de impulsionador do desenvolvimento e do crescimento econômico, com base na empresalidade do trabalhador e na lógica de produção capitalista de livre concorrência. 
Em sentido amplo, por meio da perspectiva aqui seguida, seria possível desafiar não somente o caráter anistórico e determinístico das pesquisas, como também defender a relação entre história e estudos organizacionais, como forma de confrontar diferentes alternativas em termos de orientação teórica, explicitando o componente ideológico presente nas bagagens intelectuais e testando a capacidade de generalização e a utilidade de uma teoria. Em sentido mais específico, seria possível permitir o reconhecimento de que a construção de teorias não é processo puramente metódico e definido por regras, mas também (e principalmente) um compromisso ideológico, político e moral, por meio do qual se cria e se recria o objeto de estudo escolhido.

Enfim, como último ponto, cabe ressaltar que, por mais alterações e/ou modificações que tenham ocorrido com o constructo do empreendedorismo ao longo dos anos, um elemento de continuidade adquire notoriedade: a crescente centralidade do papel da empresa neste processo. Se em um primeiro momento o empreendedor adquire papel fundamental caracterizado por sua função na sociedade, por exemplo, como comerciante, artesão ou colono (Cantillon, 1755/1950), com o passar dos anos sua imagem torna-se indissociável de sua própria organização (empreendedor clássico). Aos poucos, já em contexto histórico diferente, a função empreendedora descola-se da figura do empresário e transfere-se para a empresa por ações, que passa a prescindir deste capitalista proprietário individual, que se torna "um capitalista com salário" (Tragtenberg, 2005, p. 18). Na atualidade, ocorre o resgate da importância desse indivíduo empreendedor; agora, no entanto, novamente atrelado de forma intrínseca à organização como empreendedor organizacional, coletivo ou intraempreendedor.

Logo no primeiro parágrafo do prólogo de seu livro, Boltanski e Chiapello (2009) indagam-se acerca da complexa e idiossincrática coexistência entre a atual degradação da situação econômica e social de um número crescente de pessoas e um capitalismo em plena expansão. Como justificar e ou legitimar essa situação? Quais seriam as justificativas que, de alguma forma, sustentam as premissas capitalistas e que fazem com que os indivíduos se comprometam com elas? Assumimos neste trabalho que, sob a lógica e o controle das empresas, a ideia de empreendedorismo adquire papel primordial na sociedade: assegurar que cada indivíduo assuma, como suas, as metas de reprodução do sistema capitalista. Pode-se argumentar então que esse procedimento se desvia da busca pela emancipação humana e, ao contrário, promove formas opressivas de comportamentos individuais por meio de expectativas adequadas e formas certas de conduta, que buscam alcançar - em última análise apenas os objetivos do capital.

Artigo recebido em 01.07.2010. Aprovado em 18.11.2010.

\section{Referências}

Aidar, M. (2207). Empreendedorismo. São Paulo: Thomson Learning.

Audia, G., \& Rider, C. (2006). Entrepreneurs as organizational products: revisited. In J. Baum, R. Baron, \& M. Frese, (Eds.), The psychology of entrepreneurship (pp. 1-33). Hillsdale: Lawrence Erlbaum Associates.

Barros, A., \& Pereira, C. (2008). Empreendedorismo e crescimento econômico: uma análise empírica. Revista de Administração Contemporânea, 12(4), 975-993. doi: 10.1590/S141565552008000400005

Barros, M., \& Passos, E. (2000). Remando a favor da maré: racionalidade instrumental no curso de administração de empresas. Organizações \& Sociedade, 7(19), 161-174.

Belluzzo, L. (2005). As transformações da economia capitalista no pós-guerra e a origem dos desequilíbrios globais. Política Econômica em Foco, (7), 24-41. 
Benjamin, W. (1994). Magia e técnica, arte e política: ensaios sobre literatura e história da cultura (7a ed.). São Paulo: Brasiliense.

Boava, D., \& Macedo, F. (2009, setembro). Sentido axiológico do empreendedorismo. Anais do Encontro Nacional da Associação Nacional de Pós-Graduação e Pesquisa em Administração, São Paulo, SP, Brasil, 33.

Boltanski, L., \& Chiapello, E. (2009). O novo espírito do capitalismo. São Paulo: Martins Fontes.

Booth, C., \& Rowlinson, M. (2006). Management and organizational history: prospects. Management \& Organizational History, 1(1), 5-30. doi: 10.1177/1744935906060627

Borges, J., \& Casado, T. (2009, setembro). Empreendedores no divã: entre o Heroic Economic Superman e o Sentient Self. Anais do Encontro Nacional da Associação Nacional de PósGraduação e Pesquisa em Administração, São Paulo, SP, Brasil, 33.

Boszczowski, A. K., \& Teixeira, R. (2009, setembro). O empreendedorismo sustentável e o processo empreendedor: em busca de oportunidades de novos negócios como solução para problemas sociais e ambientais. Anais do Encontro Nacional da Associação Nacional de Pós-Graduação e Pesquisa em Administração, São Paulo, SP, Brasil, 33.

Braga, W. (2006). Meditações sobre os paradoxos do capitalismo moderno. UNIRevista, 1(3), 1-16.

Burns, T., \& DeVille, P. (2006). Teorias dos sistemas dinâmicos: teorizações sobre o capitalismo e a sua evolução. Sociologia, Problemas e Práticas, (50), 11-44.

Bygrave, W., \& Hofer, C. (1991). Theorizing about entrepreneurship. Entrepreneurship Theory and Practice, 16(2), 13-22.

Cantillon, R. (1950). Ensayo sobre la naturaleza del comercio en general. México: Fondo de Cultura Economica. (Obra original publicada em 1755)

Cardoso, F. (1964). Empresário industrial e desenvolvimento econômico no Brasil. São Paulo: Difusão Européia do Livro.

Castanhar, J. (2007). Empreendedorismo e desenvolvimento regional no Brasil: uma análise da relação entre a criação de empresas e o desenvolvimento regional ao longo do tempo e de estratégias de empreendedores selecionados (Tese de doutorado). Escola de Gestão ISCTE, Lisboa, Portugal.

Chiapello, E., \& Fairclough, N. (2002). Understanding the new management ideology: a transdisciplinary contribution from critical discourse analysis and new sociology of capitalism. Discourse Society, 13(2), 185-208. doi: 10.1177/0957926502013002406

Chieh, N., \& Andreassi, T. (2007, setembro). Intra-empreendedorismo: um estudo de caso sobre o entendimento e a aplicação dos fundamentos organizacionais associados ao termo. Anais do Encontro Nacional da Associação Nacional de Pós-Graduação e Pesquisa em Administração, Rio de Janeiro, RJ, Brasil, 31.

Chomsky, N. (2002). O lucro ou as pessoas? Neoliberalismo e ordem global. São Paulo: Bertrand Brasil.

Clark, P., \& Rowlinson, M. (2004). The treatment of history in organisation studies: towards an 'historic turn'? Business History, 46(3), 331-352. doi: 10.1080/0007679042000219175

Colbari, A. L. (2007). A retórica do empreendedorismo e a formação para o trabalho na sociedade brasileira. Revista Eletrônica de Ciências Sociais, 1(1), 75-111. 
Costea, B., Crump, N., \& Holm, J. (2006). Conceptual history and the interpretation of managerial ideologies. Management \& Organizational History, 1(2), 159-175.

Curado, I. (2001, setembro). Pesquisa historiográfica em administração: uma proposta metodológica. Anais do Encontro Nacional da Associação Nacional de Pós-Graduação e Pesquisa em Administração, Campinas, SP, Brasil, 25.

Dornelas, J. (2008). Empreendedorismo: transformando idéias em negócios. Rio de Janeiro: Elsevier/Campus.

Drucker, P. (1970). Entrepreneurship in business enterprise. Journal of Business Policy, 1(1), 3-12.

Fairclough, N. (2001). Discurso e mudança social. Brasília: UnB.

Falcon, F., \& Moura, G. (1989). A formação do mundo contemporâneo. Rio de Janeiro: Campus.

Filion, L. (1999). O empreendedorismo como tema de estudos superiores. Palestra proferida no Seminário A Universidade Formando Empreendedores, Brasília, DF, Brasil.

Fontenele, R. E. S. (2009, setembro). Empreendedorismo, competitividade e crescimento econômico: algumas evidências empíricas. Anais do Encontro Nacional da Associação Nacional de PósGraduação e Pesquisa em Administração, São Paulo, PR, Brasil, 33.

Fontenele, R. E. S., Moura, H. J., \& Leocádio, A. L. (2010, setembro). Capital humano, empreendedorismo e desenvolvimento econômico: evidências empíricas nos municípios do Ceará. Anais do Encontro Nacional da Associação Nacional de Pós-Graduação e Pesquisa em Administração, Rio de Janeiro, RJ, Brasil, 34.

Foucault, M. (2007). A ordem do discurso. São Paulo: Loyola.

Gartner, W. (1989). “Who is an entrepreneur?" Is the wrong question. Entrepreneurship Theory and Practice, 13(4), 47-68.

Garud, R., Hardy, C., \& Maguire, S. (2007). Institutional entrepreneurship as embedded agency: an introduction to the special issue. Organizational Studies, 28(7), 957-969. doi: $10.1177 / 0170840607078958$

Goldman, P. (1994). Searching for history in organizational theory: comment on Kieser. Organization Science, 5(4), 621-623. doi: 10.1287/orsc.5.4.621

Guerreiro Ramos, A. (1996). A redução sociológica. Rio de Janeiro: UFRJ.

Hobsbawn, E. (1988). A era do capital: 1848 - 1875. Rio de Janeiro: Paz e Terra.

Hobsbawn, E. (1989). A era das revoluções: 1789 - 1848. Rio de Janeiro: Paz e Terra.

Jacques, R. (2006). History, historiography and organization studies: the challenge and the potential. Management \& Organizational History, 1(1), 31-49. doi: 10.1177/1744935906060628

Kets de Vries, M. (1977). The entrepreneurial personality: person at the crossroads. Journal of Management Studies, 14(1), 34-57. doi: 10.1111/j.1467-6486.1977.tb00616.x

Kieser, A. (1994). Why organization theory needs historical analyses - and how this should be performed. Organization Science, 5(4), 608-620. doi: 10.1287/orsc.5.4.608

Konder, L. (2000). Os sofrimentos do “homem burguês”. São Paulo: Editora SENAC.

Krueger N. F., Jr., \& Brazeal, D. (1994). Entrepreneurial potential and potential entrepreneurs. Entrepreneurship Theory and Practice, 18(3), 91-104. 
Leite, E. S., \& Melo, N. M. (2008). Uma nova noção de empresário: a naturalização do 'empreendedor'. Revista de Sociologia Política, 16(31), 35-47. doi: 10.1590/S010444782008000200005

Lemos, A. (2005, setembro). Empreendedorismo no Brasil: uma atividade sem "espírito"? Anais do Encontro Nacional da Associação Nacional de Pós-Graduação e Pesquisa em Administração, Brasília, DF, Brasil, 29.

Lemos, A., \& Rodriguez, D. (2008, setembro). Empregabilidade: conquista da autonomia profissional ou nova forma de submissão? Anais do Encontro Nacional da Associação Nacional de PósGraduação e Pesquisa em Administração, Belo Horizonte, MG, Brasil, 32.

Lodi, J. (2003). História da administração. São Paulo: Pioneira Thomson Learning.

López-Ruiz, O. (2007). Os executivos das transnacionais e o espírito do capitalismo: capital humano e empreendedorismo como valores sociais. Rio de Janeiro: Azougue Editorial.

Lumpkin, G., \& Dess, G. (1996). Clarifying the entrepreneurial orientation construct and linking it to performance. Academy of Management Review, 21(1), 135-172.

Maielli, G. (2007). Counterfactuals, superfactuals and the problematic relashionship between business management and the past. Management \& Organizational History, 2(4), 275-294. doi: $10.1177 / 1744935907086115$

Maielli, G., \& Booth, C. (2008). Counterfactual history, management and organizations: reflections and new directions. Management \& Organizational History, 3(1), 49-61. doi: $10.1177 / 1744935908090997$

Marx, K., \& Engels, F. (1980). Manifesto comunista. São Paulo: CHED. (Obra original publicada em 1848)

McChesney, R. (2002). Introdução. In N. Chomsky, O lucro ou as pessoas? Neoliberalismo e ordem global (pp. 7-17). São Paulo: Bertrand Brasil.

McClelland, D. (1961). The achieving society. Princeton: Van Nostrand.

McClelland, D. (1972). A sociedade competitiva: realização e progresso social. Rio de Janeiro: Expressão e Cultura.

Mello, S. C. B., Leão, A. L. M. S., \& Paiva, F. G., Jr. (2006). Competências empreendedoras de dirigentes de empresas brasileiras de médio e grande porte que atuam em serviços da nova economia. Revista de Administração Contemporânea, 10(4), 47-69. doi: 10.1590/S141565552006000400003

Mészáros, I. (2008). A educação para além do capital. São Paulo: Boitempo.

Mintzberg, H., Ahlstrand, B., \& Lampel, J. (2000). Safári de estratégia: um roteiro pela selva do planejamento estratégico. Porto Alegre: Bookman.

Nascimento, M., Feitosa, E., Marcon, R., Verdu, F., \& Bandeira-de-Mello, R. (2007, dezembro). Ensaios teóricos: de onde vêm e para onde vão? Anais do Encontro de Ensino e Pesquisa em Administração e Contabilidade, Recife, PE, Brasil, 1.

Ogbor, J. O. (2000). Mythicizing and reification in entrepreneurial discourse ideology-critique of entrepreneurial studies. Journal of Management Studies 37(5), 605-635.

Parkinson, C., \& Howorth, C. (2007). The language of social entrepreneurs [Working Paper $\mathrm{N}^{\mathrm{o}}$ 32]. Lancaster University Management School, Lancaster, UK. 
Phillips, N., Laurence, T. B., \& Hardy, C. (2004). Discourse and institutions. Academy of Management Review, 29(4), 635-652. doi: 10.2307/20159075

Reed, M. (1999). Teorização organizacional: um campo historicamente contestado. In S. Clegg, C. Hardy, W. Nord, M. Caldas, R. Fachin, \& T. Fisher (Eds.), Handbook de estudos organizacionais (pp. 61-98). São Paulo: Atlas.

Rodrigues, A. L., \& Malo, M. C. (2006). Estruturas de governança e empreendedorismo coletivo: o caso dos doutores da alegria. Revista de Administração Contemporânea, 10(3), 29-50. doi: $10.1590 /$ S1415-65552006000300003

Rowlinson, M., Jacques, R., \& Booth, C. (2009). Critical management and organizational history. In M. Alvesson, T. Bridgmandgman, \& H. Willmott (Eds.), The Oxford handbook of critical management studies (pp. 286-303). Oxford: Oxford University Press.

Rusconi, G. (1992). Capitalismo. In N. Bobbio, N. Matteucci, \& G. Pasquino (Orgs.), Dicionário de Política (pp. 141-148). Brasília: Editora UnB.

Sader, E. (2008, setembro 4). Desequilíbrios estruturais do capitalismo atual. Le Monde Diplomatique Brasil, 14, 8-9.

Santos, B. (2002). Produzir para viver: os caminhos da produção não-capitalista. Rio de Janeiro: Record.

Santos, L. (2007). Apresentação. In O. López-Ruiz, Os executivos das transnacionais e o espírito do capitalismo: capital humano e empreendedorismo como valores sociais (pp. 11-22). Rio de Janeiro: Azougue Editorial.

Say, J. B. (1983). Tratado de economia política [Coleção Os economistas]. São Paulo: Abril. (Obra original publicada em 1803).

Schramm, C., \& Litan, R. (2008, July/August). The growth solution. The American, 32-38.

Schumpeter, J. (1961). Capitalismo, socialismo e democracia. Rio de Janeiro: Editora Fundo de Cultura. (Obra original publicada em 1942)

Schumpeter, J. (1968). Fundamentos do pensamento econômico. Rio de Janeiro: Zahar. (Obra original publicada em 1924)

Schumpeter, J. (1982). A teoria do desenvolvimento econômico [Coleção Os economistas]. São Paulo: Abril. (Obra original publicada em 1911)

Sombart, W. (1946). El apogeo del capitalismo. México: Fondo de Cultura Economica. (Obra original publicada em 1902)

Sombart, W. (1953). El burgues: contribucion a la historia moral e intelectual del hombre economico moderno. Buenos Aires: Oresme. (Obra original publicada em 1903)

Sousa, E., Oliveira, J., Filho, Fagundes, A., Dami, A., \& Lima, J. (2005, setembro). A dinâmica das ações nas organizações do terceiro setor e sua relação com o empreendedorismo social. Anais do Encontro Nacional da Associação Nacional de Pós-Graduação e Pesquisa em Administração, Brasília, DF, Brasil, 29.

Tapinos, G. (1983). Prefácio. In J. B. Say, Tratado de economia política (pp. 3-35). São Paulo: Editora Abril. 
Tasic, I. A. B., \& Andreassi, T. (2007, setembro). Estratégia e empreendedorismo: decisão e criação sob incerteza. Anais do Encontro Nacional da Associação Nacional de Pós-Graduação e Pesquisa em Administração, Rio de Janeiro, RJ, Brasil, 31.

Tragtenberg, M. (2005). Administração, poder e ideologia. São Paulo: UNESP.

Tuchman, G. (1994). Historical social science: methodologies, methods, and meanings. In N. Denzin \& Y. Lincoln (Eds.), Handbook of qualitative research (pp. 306-323) London: Sage.

Üsdiken, B., \& Kieser, A. (2004). Introduction: history in organization studies. Business History, 46(3), 321-330. doi: 10.1080/0007679042000219166

Vasconcelos, F. C., Mascarenhas, A. O., \& Kunda, G. (2007, setembro). Desenvolvimento, mudança cultural e a formação do comportamento empreendedor - um estudo de caso. Anais do Encontro Nacional da Associação Nacional de Pós-Graduação e Pesquisa em Administração, Rio de Janeiro, RJ, Brasil, 31.

Vizeu, F. (2007, setembro). Em algum lugar do passado: contribuições da pesquisa histórica para os estudos organizacionais brasileiros. Anais do Encontro Nacional da Associação Nacional de Pós-Graduação e Pesquisa em Administração, Rio de Janeiro, RJ, Brasil, 31.

Vizeu, F. (2010). Potencialidades da análise histórica nos estudos organizacionais brasileiros. Revista de Administração de Empresas, 50(1), 37-47. doi: 10.1590/S0034-75902010000100004

Walker, R. (1989). Marxism-Leninism as discourse: the politics of the empty signifier and the double bind. British Journal of Political Science, 19(2), 161-189. doi: 10.1017/S0007123400005421

Zald, M. (1993). Organization studies as a scientific and humanistic enterprise: toward a reconceptualization of the foundations of the field. Organization Science, 4(4), 513-528.

Zeitlin, J. (2008). The historical alternatives approach. In G. Jones \& J. Zeitlin (Eds.), The Oxford Handbook of Business History (pp. 120-140). Oxford: Oxford University Press. 